\title{
A utilização do LMS Chamilo na disciplina Laboratório de Ensino de Matemática: a experiência de professores em formação inicial
}

Luciane Mulazani dos Santos, UDESC, luciane.mulazani@udesc.br Ivanete Zuchi Siple, UDESC, ivanete.siple@udesc.br Emanuella Senff de Aguiar, UDESC, manu_senffy@hotmail.com Joana Steil

Alves, UDESC, joanasteil@hotmail.com

Luis Gustavo Longen, UDESC, luisglongen@gmail.com

Marcelo Sávio Ramos, UDESC, marcelo.ramos26@yahoo.com.br

Resumo: Este texto relata uma experiência de trabalho docente e discente realizada com o software livre Chamilo em uma disciplina de Laboratório de Ensino de um curso de Licenciatura em Matemática. O Chamilo é um Sistema de Gerenciamento de Aprendizagem (LMS - Learning Managment System) e foi utilizado pelos alunos da disciplina para que estes se colocassem na posição de professores-autores de cursos de conteúdos de Matemática do Ensino Médio. Assim, esses professores em formação inicial puderam exercitar a prática docente em educação a distância, experimentando as potencialidades e desafios da utilização de plataformas de LMS em processos de ensino e aprendizagem a distância.

Palavras-chaves: Chamilo, laboratório de ensino, formação inicial de professores, LMS, educação a distância.

\section{The Use of LMS Chamilo in a Laboratory for Teaching Mathematics: Experience of Teachers in Initial Training}

Abstract: This paper reports the details of an experiment with the free software Chamilo in a teaching laboratory of a Bachelor's Degree in Mathematics. Chamilo is a learning management system and was used by the students of the class so that they could place themselves as teachers-authors of course content of High School math. Thus, those teachers in initial training were able to exercise the practice of teaching in distance education, experiencing the potential and the challenges of using LMS platforms in distance teaching and learning.

Keywords: Chamilo, teaching laboratory, initial training teacher, learning management system.

\section{Introdução}

Com a crescente ampliação da disponibilidade de espaços virtuais voltados ao apoio de processos de ensino e aprendizagem, é importante que os professores estejam preparados para atuarem em ambientes da educação online. Nos cursos de formação inicial de professores, é possível iniciar a preparação desses profissionais para o trabalho com Learning Management System (LMS), ou sistemas de gestão da aprendizagem, para que assim tenham condições de prepararem e ministrarem cursos ou disciplinas de suas áreas de conhecimento utilizando os espaços virtuais.

Este texto é um relato de experiência sobre atividades realizadas em um curso de formação inicial de professores, nas quais foi experimentada e discutida a utilização de plataformas de LMS para o ensino de conteúdos de Matemática. Tais atividades foram realizadas com alunos da disciplina Laboratório de Ensino de Matemática 4 (LEM 4) do curso de Licenciatura em Matemática, em uma Universidade Pública. 
A disciplina semestral LEM 4, de 60 horas, é parte do currículo da quinta fase do curso de Licenciatura em Matemática que tem, no total, sete fases. Esta disciplina, última do rol das quatro disciplinas semestrais de laboratório de ensino do referido curso,

Tem a função comum de propiciar aos alunos do curso experiências com diferentes metodologias de ensino, materiais didáticos, conteúdos de Matemática e referenciais teóricos da Educação Matemática. Isso tudo com o intuito de capacitá-los a desenvolverem estratégias de ensino e recursos didáticos para o ensino de Matemática, bem como desenvolverem projetos e experiências educativas adequadas à escola de Ensino Fundamental e Médio. (MUNHOZ et al, 2013, p. 1)

Assim, os professores regentes das quatro disciplinas de laboratório de ensino trabalham seus conteúdos de forma a discutirem com os alunos - futuros professores de Matemática - a prática de sala de aula, sob diferentes suportes metodológicos e teóricos. No primeiro semestre de 2013, os alunos de LEM 4 utilizaram o software livre Chamilo para criarem páginas de cursos online para ensinarem conteúdos de matemática do Ensino Médio. Assim, puderam se colocar na posição de professores-autores de cursos criados em plataformas de LMS, experimentando as potencialidades e desafios de tal processo. É a partir dos resultados das atividades realizadas com o Chamilo, na disciplina de LEM 4, que este texto discute questões relacionadas com o trabalho docente com plataformas de LMS e sobre a importância do exercício dessa prática em cursos de formação inicial de professores.

\section{Software livre e LMS na educação online}

Os projetos em software livre são importantes para as instituições de ensino e para o desenvolvimento de atividades educacionais no apoio de processos de ensino e aprendizagem realizados em ambientes virtuais de aprendizagem. Isso porque, "embora não seja uma solução universal, [o software livre] pode contribuir significativamente para a disseminação e uso em larga escala de soluções eficientes e de baixo custo para a educação, a distância e mediada por computador”. (ALMEIDA, 2002). Questões como custo e liberdade devem ser levadas em conta já que contribuem para o sucesso de projetos de trabalho de professores, instrutores e instituições que se propõem a utilizar cursos ou disciplinas online, quer na educação a distância, quer como apoio na educação presencial.

Um LMS atua na automatização e na administração de cursos realizados a distância, pela internet. Usando softwares LMS, um professor cria cursos, registra e controla os acessos de alunos e tutores, prepara e disponibiliza rotas de aprendizagem, realiza avaliações, acompanha as atividades realizadas pelos alunos e seus desempenhos, entre outras ações. Há muitas soluções de LMS baseadas em software livre, vantajosas pela possibilidade do uso gratuito e livre de plataformas em constante processo de desenvolvimento e aperfeiçoamento. Um desses softwares é o Chamilo.

\section{O Chamilo e suas funcionalidades}

Chamilo é um software livre ${ }^{1}$ LMS, ou seja, um projeto de código aberto de $e$ learning e gerenciamento de conteúdo. Sua história está ligada ao desenvolvimento do LMS de código aberto Claroline na Bélgica, em 2000, pela Universidade Católica de Louvain. Em 2004, houve uma divisão na comunidade Claroline que deu início ao projeto do LMS Dokeos. Em 2010, uma nova comunidade se forma, derivada do projeto

\footnotetext{
${ }^{1}$ Publicado sob a licença GNU GPL (Licença Pública Geral)
} 
Dokeos, para iniciar o projeto do LMS Chamilo. Em junho de 2010, foi lançada a Associação Chamilo, uma organização sem fins lucrativos para cuidar do desenvolvimento do Chamilo. O LMS Chamilo permite a criação de cursos, páginas de disciplinas, grupos de trabalho e comunidades de aprendizagem em ambientes virtuais de aprendizagem, sendo uma alternativa para a realização de trabalhos colaborativos mediados pelo computador, usando a internet.

O nome Chamilo vem da palavra camaleão, o que dá uma pista sobre como esse software se adapta a diversas aplicações. Ele pode ser usado tanto para criar uma página de um professor de uma única disciplina de um curso, quanto uma página de uma Universidade com vários cursos e disciplinas. Profissionais e instituições de ensino podem adaptar o Chamilo aos seus próprios conteúdos e objetivos de ensino, não somente para cursos totalmente virtuais, mas também como apoio a cursos presenciais. Segundo dados de Chamilo (2014), vem crescendo o uso do Chamilo em outras atividades, tais como o desenvolvimento de projetos, treinamentos corporativos e instalação de grupos de estudo, ou seja, em atividades onde é importante o foco no trabalho colaborativo por meio da utilização de recursos da internet.

Chamilo é atualmente usado por milhões de estudantes de todo o mundo, e o feedback vindo da comunidade é grande. Governos, empresas privadas, universidades públicas e privadas, ONGs e outros tipos de organizações utilizam o Chamilo para gerenciarem desde pequenos treinamentos a grandes sistemas de educação a distância. [...] Chamilo é uma marca de propriedade da Chamilo VZW, uma associação sem fins lucrativos. A marca não é e nunca será de propriedade de um único detentor, reduzindo assim consideravelmente o risco de derivar da filosofia open source. Com o objetivo de proteger o software e para mantê-lo livre e aberto, a associação foi criada para vigiar o futuro do software Chamilo. (CHAMILO, 2014, tradução nossa)

Como é característico de comunidades que desenvolvem software livre, o Chamilo está em constante processo de desenvolvimento, feito de forma colaborativa por uma associação que reúne desenvolvedores e programadores em software livre, administradores de sistema, designers e professores.

De maneira acessível e intuitiva, o Chamilo apoia processos de ensino e aprendizagem que acontecem em ambientes virtuais. É de fácil instalação e também de fácil utilização, tanto para alunos quanto para professores: possui uma interface amigável, permite diferentes níveis de controle de acesso de usuários, utiliza canais de comunicação na forma síncrona e assíncrona e apresenta facilidades para a inserção e administração de conteúdos, mantendo sempre o foco nos alunos. Coloca à disposição dos usuários diversos tipos de ferramentas que permitem o trabalho com recursos que mobilizam diferentes tipos de mídias na forma de textos, imagens, áudios ou vídeos.

A criação e administração de cursos utilizando o Chamilo são feitas online, após a instalação e configuração do software que pode ser baixado do site do projeto ${ }^{2}$. Há a possibilidade de testar as funcionalidades do Chamilo criando cursos online na versão demo, sem a necessidade de instalação e configuração do software. Isso pode ser feito no ambiente Campus Chamilo ${ }^{3}$, pelo professor-autor, mediante o cadastro de um login e uma senha.

\footnotetext{
${ }^{2}$ http://www.chamilo.org/en/download

${ }^{3}$ https://campus.chamilo.org/
} 
Os conteúdos criados em um curso ambientado no Chamilo são organizados em torno de "rotas de aprendizagem", posteriormente percorridas pelos alunos. Tais rotas podem conter os seguintes recursos e atividades:

- documentos de texto criados pelo professor em páginas web ou em editores de texto ou de apresentação, utilizando arquivos de diferentes extensões, tais como doc, pdf, ppt etc..

- $\quad$ textos, imagens, vídeos e áudios, em arquivos próprios ou em links selecionados da internet;

- jogos, simuladores e aplicativos;

- exercícios avaliativos, que podem ter questões abertas, de múltipla escolha, do tipo verdadeiro ou falso, de preenchimento de lacunas;

- fóruns de discussão e chats;

- ferramentas wiki;

- ferramentas para administração do controle de acesso dos usuários.

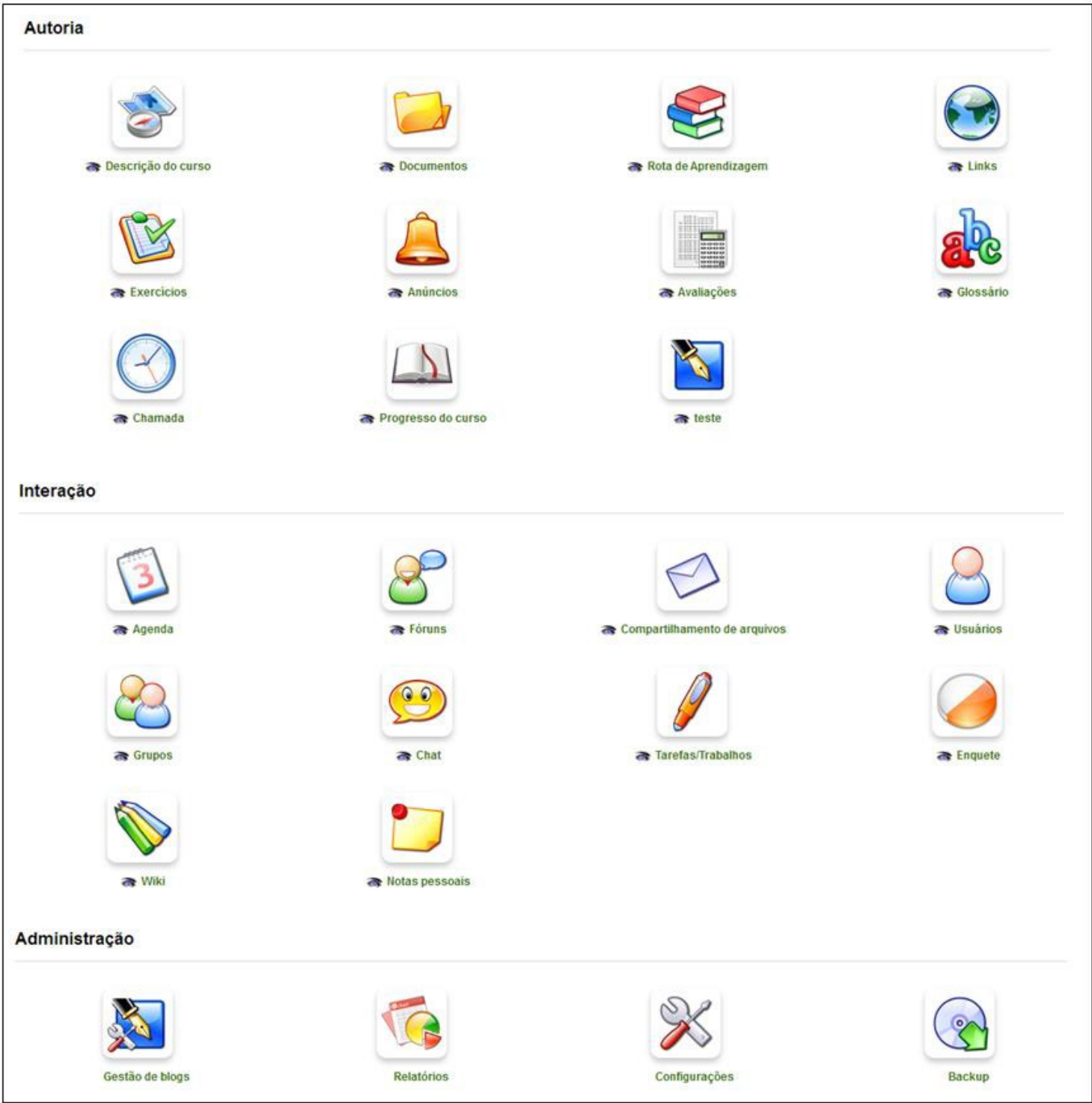

Figura 1 - Área de trabalho de um professor-autor de curso no Chamilo: tela de entrada do curso.

Fonte: https://campus.chamilo.org/ 
A área de trabalho de um professor que cria um curso no Chamilo é dividida em três espaços: autoria, interação e administração, como mostrado nas figuras 1 e 2, onde podem ser vistos os recursos e ferramentas de autoria disponíveis - representados por ícones - para a criação, estruturação e administração dos cursos. Cabe ao professor utilizá-los para organização dos conteúdos do curso em rotas de aprendizagem, para acompanhamento e organização das atividades realizadas, para comunicação e interação com os alunos e também para realização de avaliações.

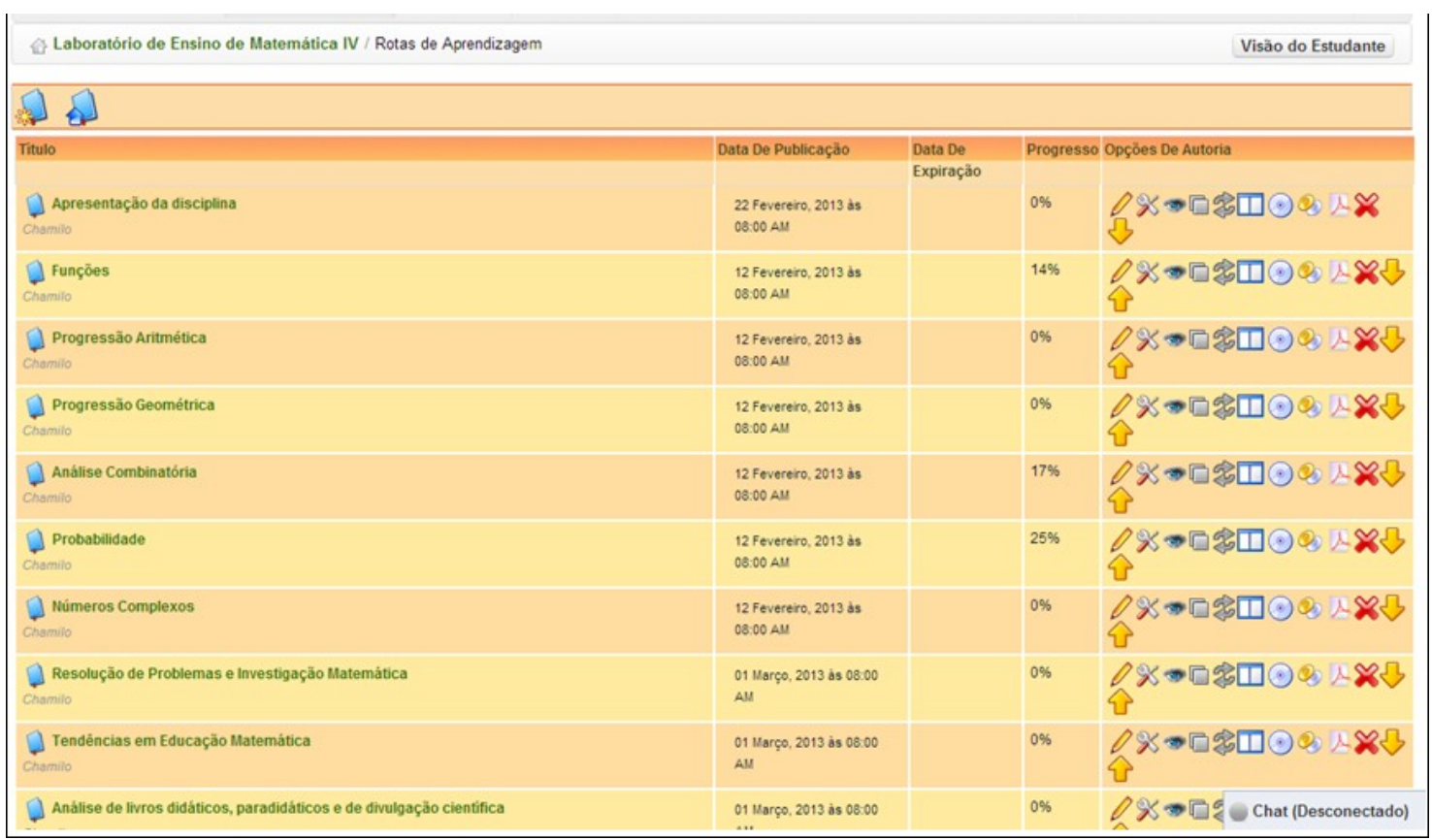

Figura 2 - Área de trabalho de um professor-autor de curso no Chamilo: tela para administração das rotas de aprendizagem.

Fonte: https://campus.chamilo.org/

O aluno, quando matriculado no curso, acessa uma área de trabalho própria, como mostrado nas figuras 3 e 4 . A organização das áreas de trabalho por tipo de usuário (professor-autor e aluno) é baseada nos direitos de cada um desses perfis dentro do sistema do curso, garantida a personalização dos acessos.

\section{Utilização do Chamilo para criação de aulas virtuais de conteúdos de matemática de Ensino Médio}

No primeiro semestre de 2013, de fevereiro a julho, os seis alunos da disciplina LEM 4 do curso de Licenciatura em Matemática utilizaram o Chamilo para desenvolverem as atividades previstas no programa curricular. De acordo com o previsto pela ementa e pelo programa dessa disciplina, os alunos devem preparar atividades de ensino relacionadas aos seguintes conteúdos de Matemática do Ensino Médio: funções, progressão aritmética e progressão geométrica, análise combinatória, probabilidade e números complexos. Os métodos didáticos utilizados pelos alunos para prepararem as suas atividades de ensino podem variar, de acordo com as orientações do docente que ministra a disciplina. Na oferta do primeiro semestre de 2013, a docente regente da disciplina acordou com os alunos a utilização do LMS Chamilo para a realização das tarefas previstas na ementa e no programa. O objetivo, com isso, foi 
oferecer aos alunos de LEM 4 a possibilidade de exercitarem uma prática docente como professores-autores de cursos em ambientes virtuais de aprendizagem.

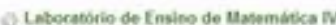

\section{5.}

Bem-vindos ao curso de

Laboratório de Ensino de Matemática IV
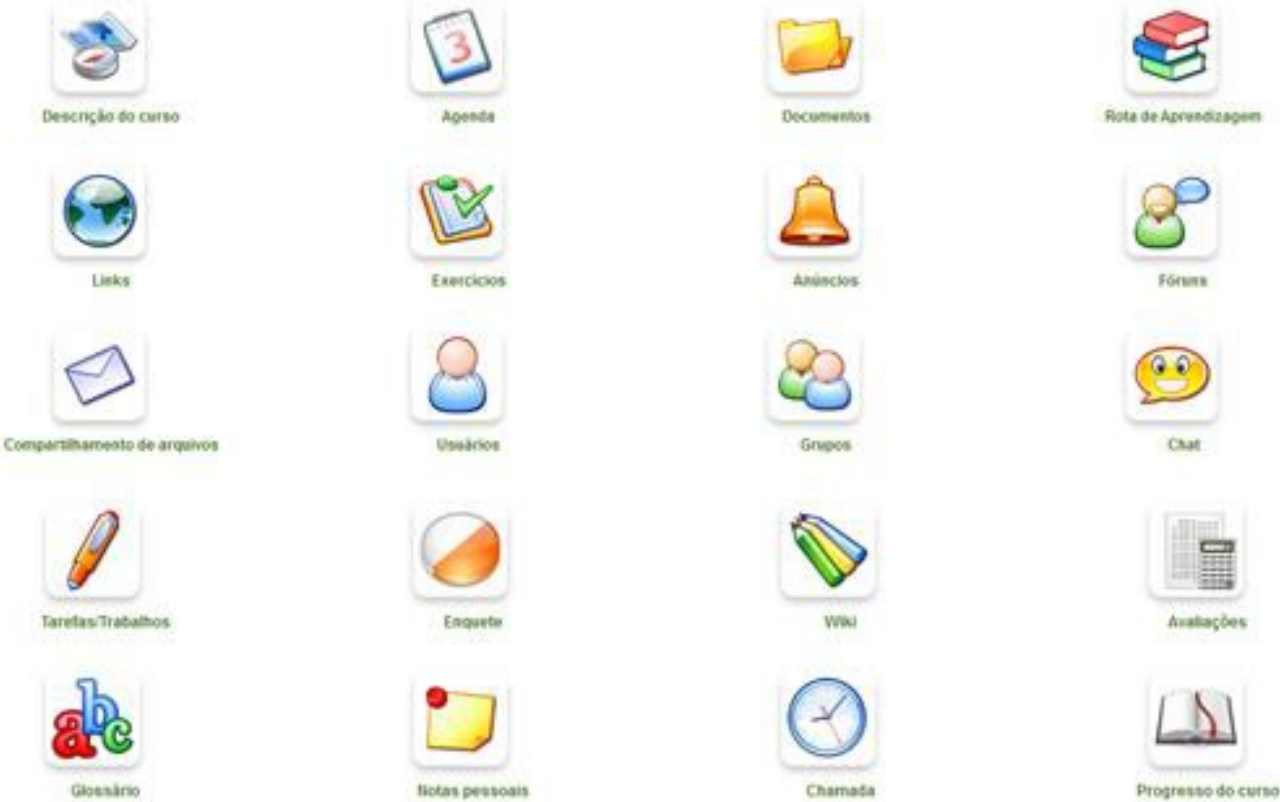

Figura 3 - Área de trabalho de um aluno matriculado em um curso no Chamilo: tela de entrada do curso

Fonte: https://campus.chamilo.org/

(10. Laboratório de Ensino de Matemática IV / Rotas de Aprendizagem

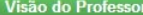

Titulo

1) Apresentaçäo da disciplina

funçōes

14

Progressão Aritmética

Progressão Geométrica

Análise Combinatória

Probabilidade

1] Números Complexos

Resolução de Problemas e Investigação Matemática

Tendências em Educação Matemática
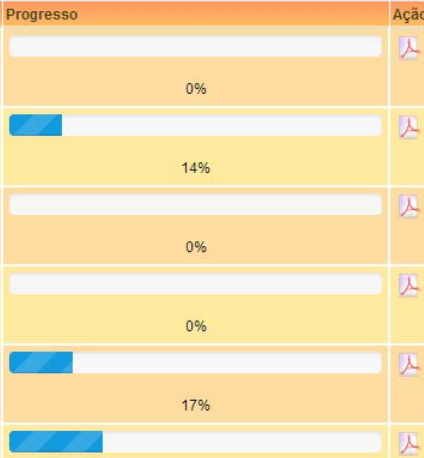

Chat (Desconectado)

Figura 4 - Área de trabalho de um aluno de um curso no Chamilo: tela de acompanhamento das rotas de aprendizagem de um curso.

Fonte: https://campus.chamilo.org/ 
Cada um dos alunos criou um curso no site Campus Chamilo, disponível como versão demo do software Chamilo, sobre um dos conteúdos do plano de ensino de LEM 4. Para isso, estudaram sobre esse software de LMS, aprenderam como configurá-lo e organizaram e gerenciaram o ambiente para suas aulas. Foram criados, então, seis cursos para o ensino de conteúdos de Matemática do Ensino Médio: funções, tipos de funções, análise combinatória, probabilidade, números complexos e progressão aritmética e geométrica. A dinâmica do trabalho com o Chamilo para a criação desses cursos seguiu as seguintes regras:

- Por sorteio, cada aluno da disciplina ficou responsável por um dos conteúdos previstos na ementa;

- O responsável pelo conteúdo deveria criar um curso no Chamilo, tornando-se, assim, professor-autor;

- Todos os alunos da disciplina deveriam se matricular e atuar como estudantes em cada um dos cinco cursos criados pelos colegas, percorrendo as rotas de aprendizagem e realizando todas as tarefas propostas;

- Os professores-autores dos cursos deveriam elaborar atividades de avaliação de seus alunos, que deveriam ser realizadas pelo Chamilo;

- Cumpridos os prazos determinados na disciplina, todos os alunos deveriam apresentar uma análise crítica sobre a utilização do Chamilo nas atividades realizadas.

A disciplina LEM 4 tem 4 aulas semanais. Para realização das atividades propostas no Chamilo, os alunos utilizaram o laboratório de informática da universidade nos horários das aulas, sendo orientados pela professora da disciplina sobre como usarem o Chamilo e sobre seus papéis como professores-autores em seus próprios cursos e como estudantes nos cursos criados pelos colegas. Desta forma, cada professorautor criou um curso sobre um dos conteúdos de matemática de Ensino Médio trabalhados na disciplina, disponibilizando recursos para aprendizagem dos colegas, que se matricularam nesses cursos como estudantes. Foi tarefa dos professores-autores criar e acompanhar as rotas de aprendizagem dos estudantes de seus cursos e foi tarefa dos estudantes dos cursos realizarem as atividades propostas nas rotas de aprendizagem criadas. Assim, todos puderam experimentar atividades do Chamilo relacionadas tanto com a posição de professor-autor de curso a distância quanto com a posição de estudantes de um curso a distância. Isso permitiu, além do acesso e conhecimento das ferramentas de um LMS, uma discussão a respeito da utilização de ambientes virtuais de aprendizagem.

As figuras 5, 6 e 7 mostram a rota de aprendizagem de um dos cursos criados com o Chamilo por alunos da disciplina LEM 4.

A avaliação dos alunos da disciplina LEM 4 levou em conta as atividades que eles realizaram tanto como professores-autores de seus cursos quanto como estudantes dos cursos dos colegas. Cada aluno, em seu curso, utilizou o sistema do Chamilo para criar uma lista de exercícios online que foi resolvida pelos colegas, estudantes do curso, e as notas aí obtidas também foram consideradas para a avaliação dos alunos de LEM 4. Finalizadas as atividades no Chamilo, os alunos da disciplina prepararam e apresentaram um texto escrito sobre a elaboração e a construção dos seus cursos discutindo aspectos tecnológicos e pedagógicos da utilização do LMS. Eles foram divididos em dois grupos: o grupo 1 escreveu sobre a utilização do Chamilo nas aulas de LEM 4 e sobre o trabalho com resolução de problemas e investigação matemática utilizando recursos tecnológicos; o grupo 2 escreveu sobre a utilização do Chamilo nas aulas de LEM 4 e sobre a tecnologia educacional como uma das tendências em Educação Matemática. Assim, o grupo 1 abordou o seguinte tema: “como as atividades 
realizadas com o Chamilo podem contribuir no trabalho do professor no uso de metodologias baseadas na resolução de problemas e investigação matemática”? Já o grupo 2 tratou de "como o uso do Chamilo em uma disciplina voltada à formação de professores de Matemática pode atuar em termos do que se espera do uso da tecnologia educacional como uma das tendências em Educação Matemática?”. Parte das considerações apresentadas pelos alunos para essas questões embasaram as considerações da seção seguinte deste artigo.

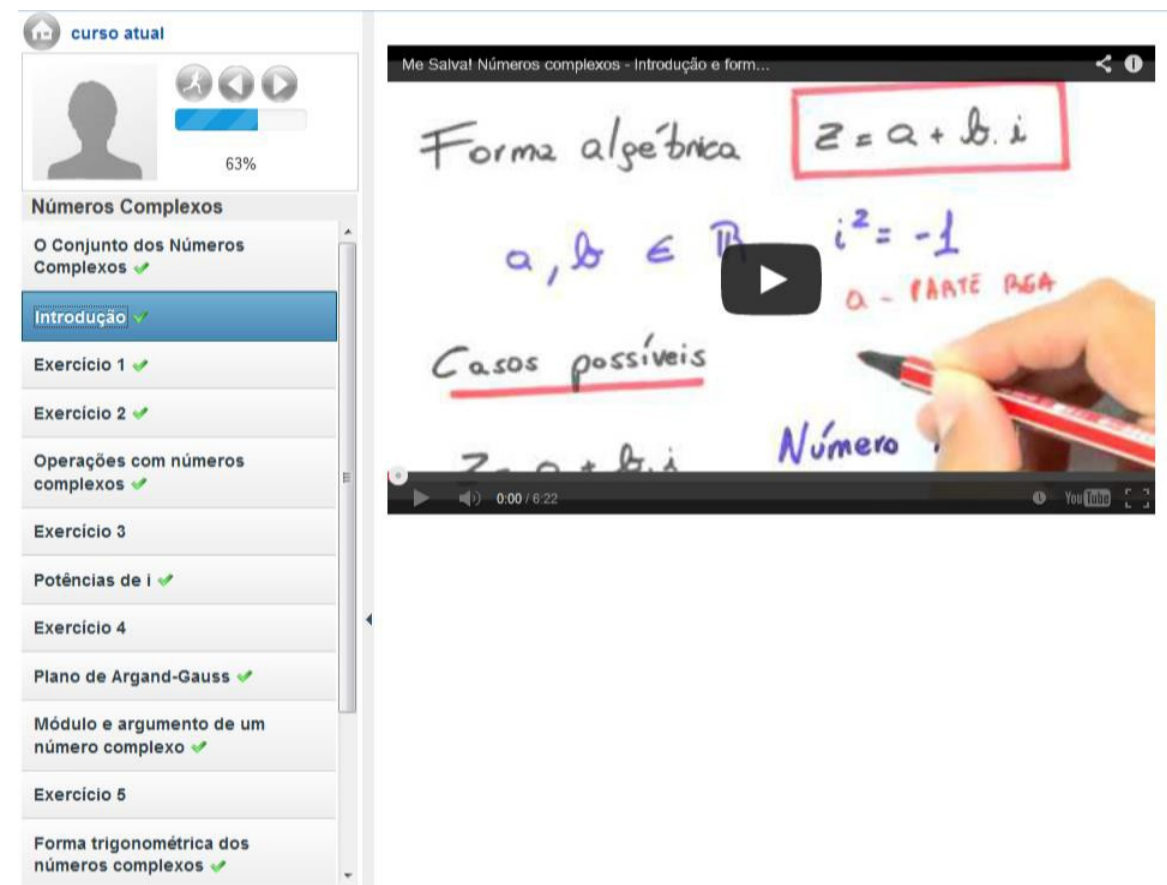

Figura 5 - Rota de aprendizagem de um curso criado com o Chamilo. Exemplo da utilização de um vídeo.

Fonte: https://campus.chamilo.org/

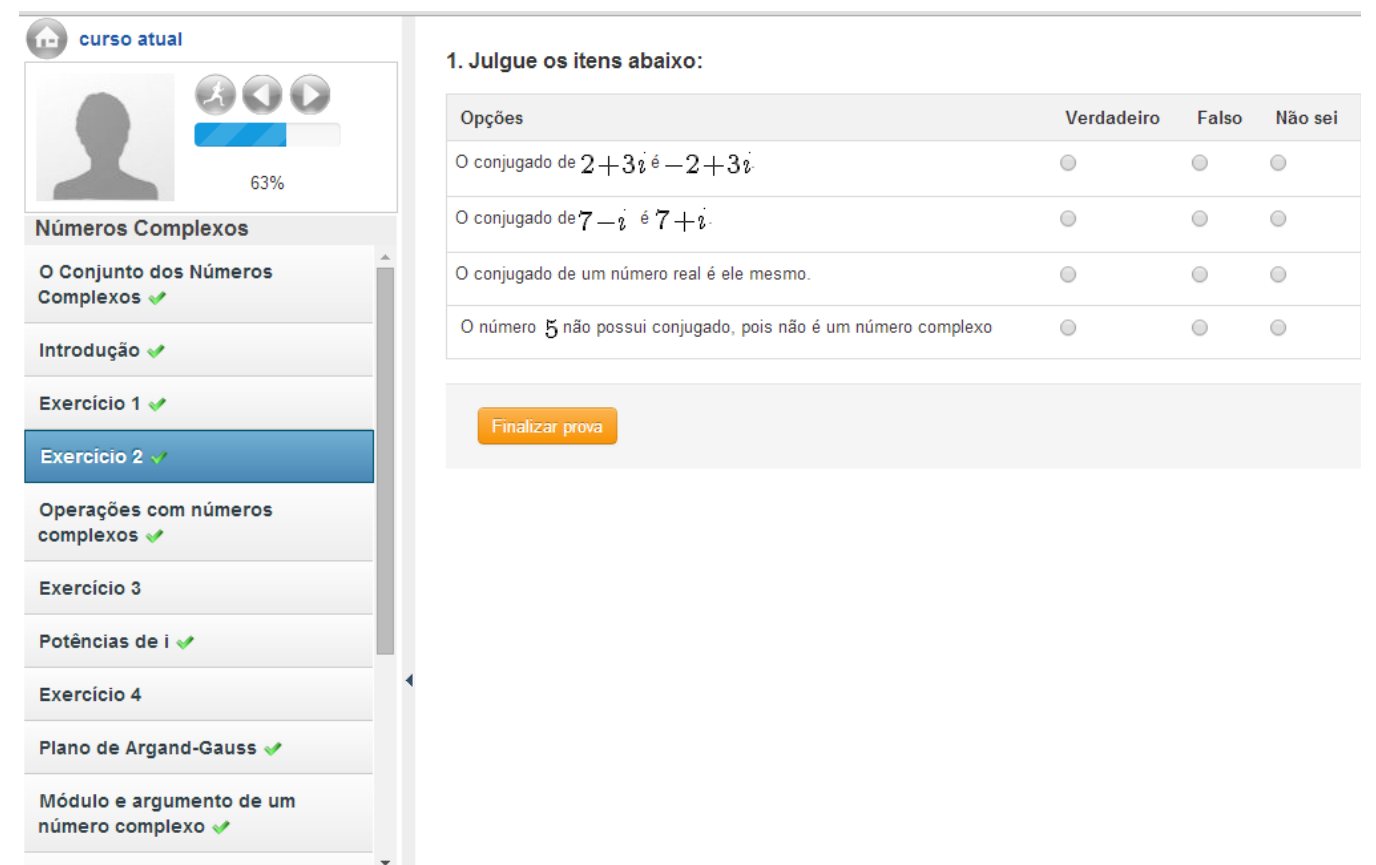

Figura 6 - Rota de aprendizagem de um curso criado com o Chamilo. Exemplo de um exercício avaliativo.

Fonte: https://campus.chamilo.org/ 


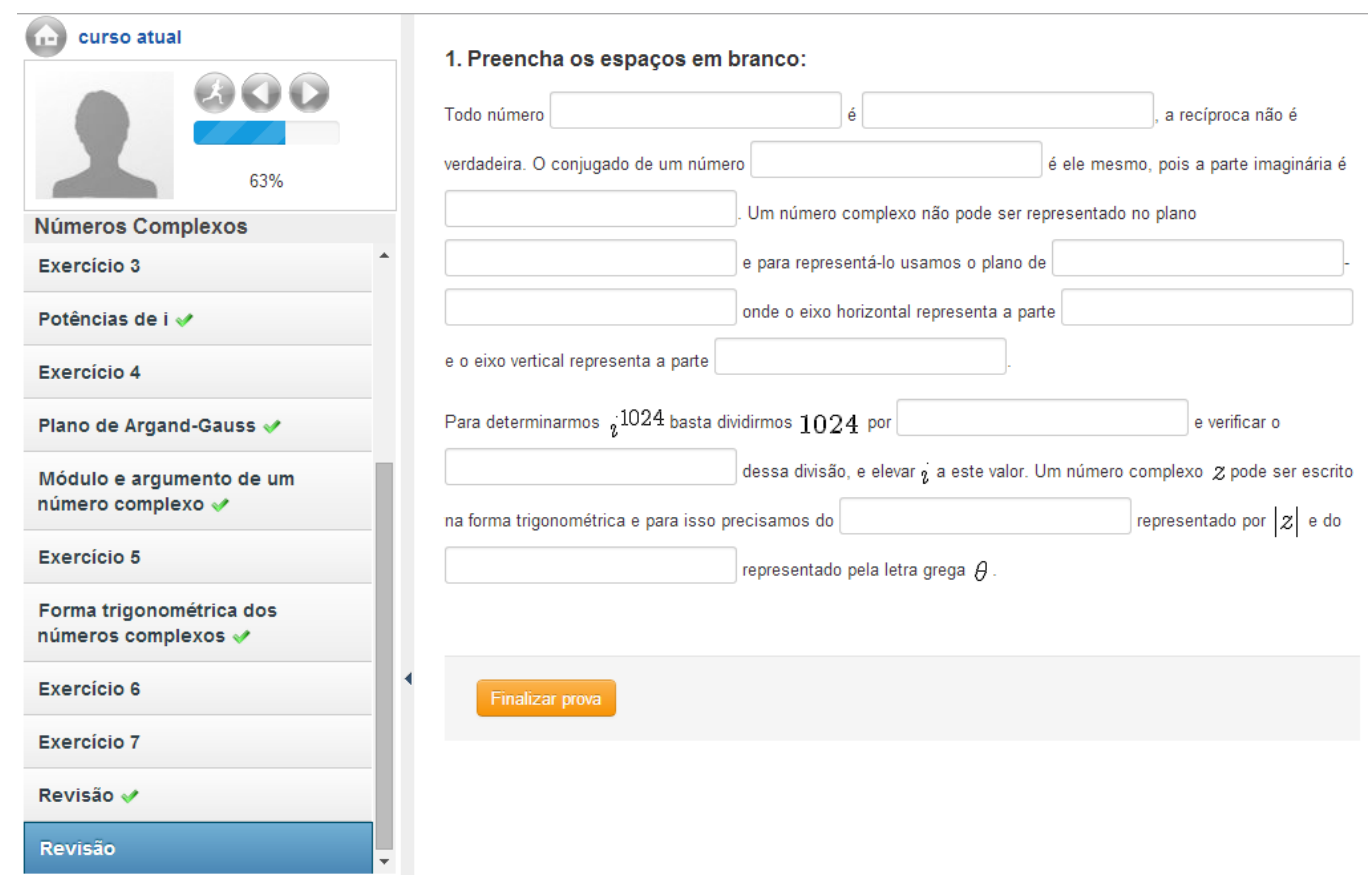

Figura 7 - Rota de aprendizagem de um curso criado com o Chamilo. Exemplo de um exercício avaliativo.

Fonte: https://campus.chamilo.org/

\section{Considerações finais sobre o trabalho com LMS na formação inicial de professores}

Assim como o mundo está em constante mudança, é preciso que as metodologias de ensino também passem por melhorias que correspondam às novas tecnologias. Para isto, é importante que educadores tenham formação para utilizarem ferramentas tecnológicas que apoiem os processos de ensino e aprendizagem. A abordagem de disciplinas com objetivos voltados para a área de educação nos cursos de licenciatura é muito importante para que os futuros professores formem-se, além de especialistas em suas áreas, educadores. É indispensável que o professor busque metodologias que favoreçam o aprendizado de determinados conteúdos. Os cursos de formação de professores devem se preocupar em bem preparar os seus alunos tanto com relação aos conteúdos disciplinares diretamente relacionados com a área de formação quanto com aqueles ligados ao exercício da profissão. Assim, por exemplo, no curso de Licenciatura em Matemática, tanto é importante que os alunos tenham uma sólida formação em Cálculo Diferencial e Integral quanto que tenham acesso e exercitem práticas e discussões críticas de qualidade a respeito de metodologias de ensino de Matemática. Tratando especificamente do uso da tecnologia na educação, é fundamental que as questões relacionadas com a utilização de espaços virtuais para ensino e aprendizagem tenham o seu espaço nos currículos dos cursos de formação de professores. Uma disciplina de Laboratório de Ensino, como a que teve sua prática descrita neste artigo, é um dos espaços privilegiados onde podem ser tratadas essas questões.

O Chamilo proporcionou aos alunos da $5^{\text {a }}$ fase do curso de Licenciatura em Matemática a experiência de ministrarem aulas de uma maneira bastante inovadora, exercitando uma prática que fugiu dos conceitos de aula tradicional. Isto possibilitou a eles o contato com a preparação de aulas, a elaboração e seleção de materiais para o ensino a distância. Portanto, a utilização desta ferramenta nas aulas de LEM 4 tornou esses professores em formação mais bem preparados para futuramente lidarem com este e outros tipos de tecnologias. Quando os professores em formação podem experimentar 
atividades docentes em LMS como o Chamilo, onde se colocam na posição de autores de cursos vivenciando um aspecto diferenciado da profissão, tomam contato com uma situação que pode ajudá-los no exercício futuro da profissão de professor. Ficará mais fácil, tendo conhecimento prévio, assumir funções que requerem sua atuação em ambientes virtuais de aprendizagem. Se, junto com essa experiência como professoresautores se colocam também com estudantes em cursos criados por seus colegas, conseguem perceber os dois lados de um mesmo sistema, entendendo melhor muitas das particularidades de processos de ensino e aprendizagem, tantos virtuais como presenciais. Assim, uma das maiores potencialidades do uso de LMS no trabalho com professores em formação é a oportunidade de colocá-los frente a frente com as tarefas de um professor atuante em ambientes online, ou seja, daquele que utiliza os recursos da tecnologia da informação e comunicação como apoio às suas atividades de ensino. Além disso, um LMS como o Chamilo dá a alunos e professores a chance de se envolverem em atividades de educação online realizando um trabalho de construção de conhecimento de modo colaborativo, aberto, livre e baseado na autonomia. No papel de professores-autores em disciplinas online, os alunos tiveram que, além de planejarem as aulas, encontrar a melhor maneira de organizar os conteúdos utilizando os recursos oferecidos pela plataforma. Precisaram aprender sobre gerenciamento de cursos em plataformas de LMS.

E aí, passamos a discutir um dos desafios do uso de LMS: o trabalho com a pesquisa, seleção e organização de recursos para a criação de cursos a distância. É importante que os professores se atentem para a importância de se colocarem no lugar dos alunos quando selecionam textos, áudios, imagens, vídeos que irão compor as rotas de aprendizagens para que se levem em conta, de maneira adequada, elementos como tempo de duração do curso, formas de avaliação, formas de comunicação e interação. Além disso, é importante conhecerem bem a plataforma de LMS usada com relação à segurança, estabilidade, condições de acesso, organização, interface e atualização.

Considerando as potencialidades e desafios do uso do Chamilo como LMS, experimentado nas aulas de Laboratório de Ensino de Matemática, conforme a prática relatada neste texto, tanto a professora regente da disciplina quanto os alunos que a cursaram consideraram positivo o trabalho com a utilização de um sistema de gerenciamento de aprendizagem no curso que forma professores de Matemática.

\section{Referências}

ALMEIDA, R.Q. Software Livre na Educação. Boletim EAD, Campinas, p. 100-103, 2002.

CHAMILO. E-learning and colaboration software. Disponível em: < http://www.chamilo.org/en/about-chamilo> Acesso em: 20/03/2014.

MUNHOZ, R. H. ; SANTOS, L. M. ; SIPLE, I. Z. ; AGUIAR, R. ; LUIZ, L. S. O Laboratório de Ensino de Matemática como disciplina curricular e espaço diferenciado na formação inicial do professor de Matemática. In: Encontro Nacional de Educação Matemática, 11., 2013, Curitiba. Anais. Curitiba: Sociedade Brasileira de Educação Matemática. 